\title{
A PERSPECTIVA DE GÊNERO E RAÇA NAS POLÍTICAS PÚBLICAS NO CENÁRIO NEOLIBERAL: UMA ANÁLISE DA AGENDA GOVERNAMENTAL PIAUIENSE
}

Hilziane Layza de Brito Pereira Lima ${ }^{1}$

\section{RESUMO}

A violência de gênero têm sido intensamente debatida na cena contemporânea, mormente devido aos índices elevados de feminicídio, o que requer uma postura ativa por parte do Estado a fim de se resguardar socialmente as mulheres em situação de violência. Este artigo pondera a respeito da formatação das políticas públicas na agenda governamental do Estado do Piauí sob a perspectiva do gênero e da raça, com o objetivo de verificar a presença e estrutura de políticas públicas voltadas especificamente às mulheres negras em situação de violência no cenário neoliberal. A partir de um estudo descritivo e qualitativo, o trabalho se desenvolveu mediante revisão sistemática de literatura sobre o tema e através da análise documental de arquivos disponíveis no site oficial do Governo do Estado do Piauí. Aponta-se ao final a carência de políticas públicas no Estado do Piauí destinadas especialmente à mulher negra em situação de violência.

Palavras-Chave: Políticas Públicas. Gênero. Raça.

\section{INTRODUÇÃO}

Os elevados índices de violência de gênero têm demandado a atuação estatal através de implementação e execução de políticas públicas que visem resguardar socialmente as mulheres, promovendo a equidade de gênero nas políticas públicas e exigindo um reconhecimento das diferenças entre as mulheres em situação de violência.

A violência invisível provocada pela superioridade da "branquitude" no imaginário da sociedade promove efeitos negativos na subjetividade de mulheres

\footnotetext{
${ }^{1}$ Professora Efetiva de Direito da Universidade Estadual do Piauí (UESPI); Mestranda em Políticas Públicas pela Universidade Federal do Piauí (UFPI); Graduada em Direito pela Universidade Estadual do Piauí (UESPI); Advogada; Especialista em Direito e Processo do Trabalho; Especialista em Docência do Ensino Superior. Email: hilzianebrito@hotmail.com
} 
negras, afetando suas relações de ordem ocupacional, relacional e até mesmo sexual. Esses efeitos evidenciam a necessidade de se criar ou remodelar algumas práticas afetadas pelo neoliberalismo político, que pressupõe uma igualdade entre todos, transferindo a responsabilidade social do Estado para os indivíduos.

As demandas das mulheres pela equidade de gênero foram levadas à esfera pública, apontando para a necessidade de se ponderar sobre "equidade de gênero" nas políticas públicas. Esse processo de participação e reivindicação remete ao conceito de cidadania e democracia com a participação cada vez mais frequente na agenda pública em torno de questões gerais relativas à democratização, como de uma pauta específica de reclamações por serviços públicos. Os movimentos sociais feministas tiveram participação relevante neste processo.

Desta feita, este artigo analisa a formatação da questão de gênero e raça nas políticas públicas na agenda governamental do Estado do Piauí como referência no enfrentamento à violência de gênero contra as mulheres negras no cenário neoliberal.

Quanto à abordagem metodológica, a pesquisa se desenvolveu a partir de um estudo descritivo e qualitativo. $\mathrm{O}$ artigo é fruto de uma revisão sistemática de literatura, utilizando-se como parâmetro as obras de Kimberlé Crenshaw (2002), Angela Davis (2016), Biroli (2018), Bell Hooks (2015), Pierre Bourdieu (1999) e Heleieth Saffioti (2004), que abordam a relação entre patriarcado e a violência de gênero, dentre outros.

Em um segundo momento, realizou-se uma análise de conteúdo por meio de pesquisa no site oficial do Governo do Estado do Piauí, a fim de verificar as ações que guardam relação com as políticas públicas para o enfrentamento à violência de gênero contra as mulheres negras no estado piauiense na era neoliberal.

Não obstante o Estado do Piauí, objeto desta pesquisa, tenha se destacado nacionalmente nos últimos anos pela elaboração e implementação de políticas públicas destinadas ao amparo da mulher piauiense em situação de violência, não se é possível vislumbrar, a partir da análise documental realizada, uma ação governamental voltada mais especificamente para tratar a violência de gênero em face da mulher negra, ainda vista e analisada no conjunto da totalidade. 


\section{coNGBESSOCOENICIAESOCIEDADE

\section{METODOLOGIA}

Quanto à abordagem metodológica, a pesquisa foi realizada a partir de um estudo predominantemente descritivo e qualitativo. A opção pela abordagem qualitativa se ajustou na afirmação que esta abordagem comporta o aprofundamento de questões no âmbito das definições e valores que se expressam no campo das relações e reproduções sociais, de acordo com Minayo (2001):

A pesquisa qualitativa responde a questões muito particulares. Ela se preocupa, nas ciências sociais, com um nível de realidade que não pode ser quantificado. Ou seja, ela trabalha com o universo de significados, motivos, aspirações, crenças, valores e atitudes, o que corresponde a um espaço mais profundo das relações, dos processos e dos fenômenos que não podem ser reduzidos à operacionalização de variáveis. (MINAYO, 2001, p. 22).

A análise foi desenvolvida em dois momentos, o teórico e o documental, iniciando com a pesquisa teórica a partir de uma revisão bibliográfica, a fim de se oportunizar a compreensão de conceitos relevantes ao tema. Para tanto, foram utilizados como parâmetro os estudos das autoras Kimberlé Crenshaw (2002), Angela Davis (2016), Biroli (2018), Scott (1989), Bell Hooks (2015) e Adriana Piscitelli (2008), dentre outras que se destacam na temática, que ajudaram a compreender a interseccionalidade entre eixos de poder e como se caracteriza essa discriminação interseccional. O trabalho também retomará escritos de Heleieth Saffioti (2004) e Pierre Bourdieu (1998), que abordam a relação entre patriarcado e a violência de gênero.

Posteriormente, foi realizada a pesquisa documental, mediante o método de análise de conteúdo. Para Bauer (2000, p. 212) a análise de conteúdo “[...] foi desenvolvida, na pesquisa social, para a análise de materiais textuais, especificamente material impresso". Bardin (2016, p. 125), por sua vez, explicita as fases da análise de conteúdo em torno de "três polos cronológicos: pré-análise, a exploração do material e o tratamento dos resultados, inferências e interpretação". 


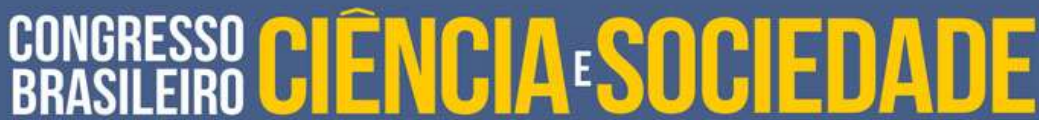

Dessa forma, a análise de conteúdo foi desenvolvida com a pesquisa de documentos públicos a nível estadual que guardam relação com as políticas públicas para o enfrentamento à violência de gênero, a fim de verificar a presença e estrutura de políticas públicas voltadas especificamente às mulheres negras em situação de violência no Estado do Piauí.

\section{RESULTADOS E DISCUSSÕES}

O Atlas da Violência de 2019 revelou que 87\% das vítimas de homicídios do Estado do Piauí foram negros. Pesquisa realizada pela Secretaria Municipal de Políticas Públicas Para Mulheres de Teresina - PI (SMPPM), apresentada no início do ano de 2018, aponta que em 2017 foram registrados mais de 8 (oito) mil casos de violência contra a mulher no Piauí.

A Constituição Federal de 1988 representa um marco essencial na instituição da cidadania e dos direitos humanos das mulheres no Estado brasileiro, pois deu importância ao cumprimento das políticas sociais:

A partir da Constituição de 1988, as políticas sociais brasileiras têm como finalidade dar cumprimento aos objetivos fundamentais da República, conforme previsto no seu art. 3‥ Assim, por intermédio da garantia dos direitos sociais, buscou-se construir uma sociedade livre, justa e solidária, erradicando a pobreza e a marginalização, reduzindo as desigualdades sociais e regionais e promovendo o bem de todos, sem preconceitos ou quaisquer formas de discriminação (CASTRO, 2009, p. 93).

Apesar de muitos avanços internos e externos, ainda persistem elementos discriminatórios com relação às mulheres no pensamento social do brasileiro. Não obstante, o reconhecimento por parte dos governos da situação peculiar em que vivem muitas mulheres é considerado um grande progresso na pauta de reivindicações de políticas públicas de gênero. 


\section{GONGGESSOCIENCIAESOCIEDADE

Para Castro (2009), a partir do Governo Lula essa pauta passou a ser inserida de forma mais concreta na agenda governamental:

O governo Lula, logo em seu início, reconheceu que eram inúmeros os problemas sociais a serem enfrentados pela sociedade brasileira. [...] Com o intuito de enfrentar esses desafios, o governo do presidente Lula desencadeou, em seu início, uma série de medidas políticoadministrativas, que podem ser agrupadas da seguinte forma: [...] a política de promoção da igualdade de gênero, impulsionada pela Secretaria Especial de Políticas para as Mulheres (CASTRO, 2009, p. 103)

As políticas públicas são compreendidas como a forma pela qual o Estado atua para amenizar os conflitos e desigualdades sociais, constituídas do relacionamento e dos interesses que permeiam as diversas facetas da sociedade. Dessa forma, as políticas públicas representam a execução de ações pelo Estado. Rodrigues (2010) aponta que:

Políticas públicas são ações de Governo, portanto, são revestidas da autoridade soberana do poder público. Dispõem sobre "o que fazer" (ações), "aonde chegar" (metas ou objetivos relacionados ao estado de coisas que se pretende alterar) e "como fazer" (estratégias de ação) (RODRIGUES, 2010, p. 53).

Os elevados índices de violência de gênero têm demandado a atuação estatal através de implementação e execução de políticas públicas que visem resguardar socialmente as mulheres, promovendo a equidade de gênero nas políticas públicas e exigindo um reconhecimento das diferenças entre as mulheres em situação de violência.

Para Scott (1989) o conceito de gênero é utilizado para apontar relações sociais entre os sexos, rejeitando justificativas biológicas, sendo uma ferramenta para indicar construções sociais:

"Gênero", como substituto de "mulheres", é igualmente utilizado para sugerir que a informação a respeito das mulheres é necessariamente informação sobre os homens, que um implica no estudo do outro. Este uso insiste na ideia de que o mundo das mulheres faz parte do mundo 


\section{conVersSO CIENCIA:SOCIEDADE

dos homens, que ele é criado dentro e por esse mundo. Esse uso rejeita a validade interpretativa da ideia das esferas separadas e defende que estudar as mulheres de forma separada perpetua o mito de que uma esfera, a experiência de um sexo, tem muito pouco ou nada a ver com o outro sexo (SCOTT, 1989, p. 7).

Contudo, vive-se contemporaneamente em um estado neoliberal que transfere para o particular a responsabilidade social que lhe cabe, o que repercute negativamente nas técnicas governamentais. A ausência de um recorte de raça, de ausência de um olhar para as diversas clivagens sociais marcadoras da diferença, afeta de sobremaneira a adoção e implementação de políticas para aqueles mais afetados pelas mazelas sociais, à revelia de todo um processo histórico criador de inúmeras desigualdades.

A localização interseccional das mulheres negras e sua marginalização estrutural promovem a exclusão racial decorrente do universalismo das políticas públicas de enfrentamento à violência, não se observando o falo de que as mulheres negras estão localizadas em um ponto de subordinação recorrente se comparadas às mulheres brancas.

Akotirene (2019) destaca que a interseccionalidade instrumentaliza as instâncias de proteção aos direitos humanos a lidarem com as necessidades e reivindicações das mulheres negras:

A despeito dos direitos humanos permitirem acesso irrestrito, independentemente de raça, sexo, nacionalidade, etnia, idioma, religião ou qualquer outra condição, as mulheres negras se veem diante dos expedientes racistas e sexistas das instituições públicas e privadas por thes negarem primeiro trabalho e, depois, o direito humano de serem reclamantes das discriminações sofridas (AKOTIRENE, 2019, p. 62).

Para Crenshaw (2002), é conferido um grau de invisibilidade às questões referentes a mulheres marginalizadas, dificultando a identificação da discriminação interseccional em conjunturas onde forças econômicas, culturais e sociais discretamente amoldam o pano de fundo, posicionando as mulheres em um ponto onde são afetadas por outros sistemas de subordinação. E complementa: 


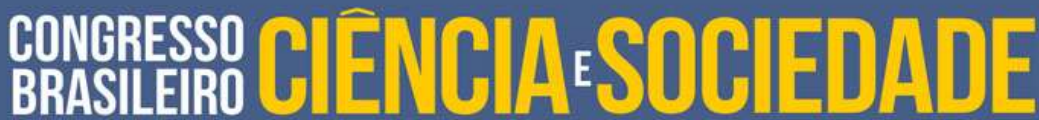

Portanto, a atenção à subordinação interseccional exige uma estratégia que valorize a análise de baixo para cima, começando com o questionamento da maneira como as mulheres vivem suas vidas. $\mathrm{A}$ partir daí, a análise pode crescer, dando conta das várias influências que moldam a vida e as oportunidades das mulheres marginalizadas. É especialmente importante descobrir como as políticas e outras práticas podem moldar suas vidas diferentemente de como modelam as vidas daquelas mulheres que não estão expostas à mesma combinação de fatores enfrentados pelas mulheres marginalizadas (CRENSHAW, 2002, p. 182).

Para Crenshaw (2002), as políticas e as normas nem sempre são capazes de prever que as mulheres são ao mesmo tempo negras e mulheres. Daí decorre a necessidade de se analisar as experiências das mulheres marginalizadas, de modo a refletir sobre suas múltiplas identidades, promovendo-Ihes visibilidade e desvendando as formas de subordinação que convergem para oprimir. Urge-se garantir que a discriminação racial e de gênero que afeta mulheres negras sejam consideradas simultaneamente, sem exclusão. A autora assim conceitua o termo interseccionalidade:

"[...] uma conceituação do problema que busca capturar as consequências estruturais e dinâmicas da interação entre dois ou mais eixos da subordinação. Ela trata especificamente da forma pela qual o racismo, o patriarcalismo, a opressão de classe e outros sistemas discriminatórios criam desigualdades básicas que estruturam as posições relativas de mulheres, raças, etnias, classes e outras. Além disso, a interseccionalidade trata da forma como ações e políticas específicas geram opressões que fluem ao longo de tais eixos, constituindo aspectos dinâmicos ou ativos do desempoderamento (CRENSHAW, 2002, p. 177).

Quanto à adoção de políticas públicas de enfrentamento à violência de gênero, especificamente a violência contra a mulher, o Estado do Piauí tem assumido posto de destaque a nível nacional, desenvolvendo várias ações de fortalecimento das políticas públicas para a proteção da mulher. Tanto é que o estado foi escolhido em 2016 para 


\section{coNpGESSOCOENICIAESOCIEDADE

elaborar as diretrizes em comemoração a um ano da Lei de Feminicídio (Lei n. 13.104/2015).

Uma das políticas criadas pelo Governo do Piauí com o escopo de facilitar denúncias de casos de violência contra a mulher é o aplicativo "Salve Maria", lançado em 2017, um aliado da polícia que permite o envio sigiloso de mensagens que chegam até o servidor público responsável para a tomada de providências cabíveis.

Importante destacar a parceria com o Governo Federal em dois programas de sua iniciativa: o "Pró-equidade de Gênero e Raça" e a "Unidade Móvel de Atendimento às Mulheres Vítimas de Violência". O primeiro tem como fim promover a igualdade de oportunidades e de tratamento entre homens e mulheres nas organizações públicas e privadas. O segundo, desenvolvido a partir de unidades móveis e adaptadas que percorrem mensalmente diversos municípios, promove ações de orientação, informação e enfrentamento à violência contra as mulheres (Disponível em: <http://www.pi.gov.br/materia/coordenadoria-de-mulheres/coordenadoria-damulher-desenvolve-acoes-de-enfrentamento-a-violencia-em-municipios-do-piaui1785.html> Acesso em: 01 de jul. 2019).

Em 2004 foi criada a "Casa Abrigo Mulher Viva", mantida pelo Governo do Estado através da SASC (Secretaria da Assistência Social e Cidadania) e da CEPM (Coordenadoria de Estado de Políticas para as Mulheres). A Casa protege mulheres vítimas de violência doméstica e familiar durante o período de até três meses em que estejam em situação de violência e risco de morte (Disponível em: < http://www.sasc.pi.gov.br/noticia.php?id=799> Acesso em: 26 de jun. 2019).

Já o "Centro de Referência para Mulheres Vítimas de Violência Francisca Trindade", por sua vez, criado em 2007, se volta à promoção do bem estar e à cidadania da mulher, fornecendo atendimento psicossocial e jurídico e realizando campanhas de orientação e informação às mulheres quanto a seus direitos (Disponível em: < http://www.sasc.pi.gov.br/noticia.php?id=799> Acesso em 26 de junho de 2019).

Implementado em 2004, o Serviço de Atendimento às Mulheres Vítimas de Violência Sexual (SAMVVIS), disponibiliza às mulheres uma equipe multiprofissional que 


\section{coNGBESSOCOENICIAESOCIEDADE

ampara as mulheres vítimas de violência sexual, em âmbito estadual, incluindo a prevenção de doenças sexualmente transmissíveis (DST) e da gravidez indesejada (Disponível em: <http://www.mder.pi.gov.br/conheca/samvvis/> Acesso em 30 de jun. 2019). Aludido serviço funciona 24 horas por dia e oportuniza a feitura do exame de corpo de delito na própria Maternidade Evangelina Rosa, na cidade de Teresina, a fim de humanizar o atendimento.

De suma importância também os vários Centros de Referência da Assistência Social (CRAS) e Centros de Referência Especializado da Assistência Social (CREAS). Ademais, o Estado ainda conta com o funcionamento de quatro Delegacias de Proteção dos Direitos da Mulher na capital Teresina e, no interior do Estado, em Parnaíba, Campo Maior, Piripiri, Picos, Oeiras, Floriano, São Raimundo Nonato, Bom Jesus e Corrente.

Possui três Defensorias Públicas da Mulher (Núcleo de Defesa da Mulher em Situação de Violência) e o Núcleo de Promotorias de Justiça de Defesa da Mulher Vítima de Violência Doméstica e Familiar Contra a Mulher (NUPEVID), desenvolvido pelo $\begin{array}{llll}\text { Ministério } & \text { Público } & \text { (Disponível }\end{array}$ <http://www.tjpi.jus.br/portaltjpi/coordenadoria-da-mulher/rede-de-atendimento-amulher-em-situacao-de-violencia/> Acesso em: 30 de jun. 2019).

O Município de Teresina tem colaborado de forma considerável nas atividades de enfrentamento à violência contra a mulher com duas relevantes políticas públicas: 0 Centro de Referência Esperança Garcia e o Programa Amor de Tia, que contam com uma rede especializada de atendimento às mulheres vitimadas pela violência.

De fato, evidencia-se um certo destaque do Estado do Piauí na implementação e execução de políticas públicas voltadas ao enfrentamento da violência de gênero, motivo pelo qual tem recebido comitivas de outros governos, a fim de que possam levar a experiência desenvolvida aqui.

Todavia, não se vislumbrou a existência de políticas públicas específicas ao enfrentamento dessa questão que tenha recortes, ao mesmo tempo, de gênero e raça. As políticas públicas mencionadas se voltam à mulher em geral, não se delimitando categorias identitárias. Ou seja, não se verificou política pública que seja capaz de 


\section{coNGGESSOCOENCIAESOCIEDADE

reconhecer e tratar de discriminações entrecruzadas de gênero, raça, classe ou outras categorias de identidades.

São, portanto, marcadores sociais que diferenciam as mulheres em diversos aspectos, seja pela sua cor, pela sua opção sexual, pela sua classe social. Estes elementos precisam ser analisados em conjunto com outros elementos na implementação e execução de políticas públicas, possibilitando a observação específica de que um determinado grupo pode sofrer mais discriminação do que outro, abrindo vantagem de oportunidades para este último.

\section{CONSIDERAÇÕES FINAIS/CONCLUSÕES}

É digno de reconhecimento a presença da pauta de reivindicações de políticas públicas de gênero na agenda dos governos. Contudo, da análise realizada, conclui-se que, não obstante ser utilizado como parâmetro por outros estados da federação no quesito enfrentamento à violência contra a mulher e a presença da questão de gênero na agenda governamental piauiense, não se verificou a existência de uma política pública específica, com recorte de gênero e raça, que se volte a enfrentar os marcadores sociais da diferença que oprimem as mulheres negras.

Dados de que a maior parte das mulheres que sofre violência de gênero são negras exigem uma relação mais estreita entre o que se vive e como as políticas públicas tratam essa vivência. Eis um dos grandes desafios da interseccionalidade em uma sociedade universalista e de perfil neoliberal.

\section{REFERÊNCIAS}

AKOTIRENE, Carla. Interseccionalidade. São Paulo: Sueli Carneiro; Pólen, 2019. 


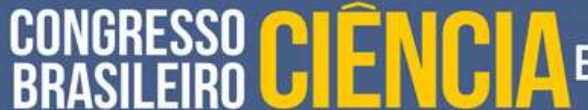

ANAIS CBCS 2019 | 3 a 5 de outubro de 2019 | Centro Universitário Santo Agostinho - Teresina - PI

Atlas da violência 2019. / Organizadores: Instituto de Pesquisa Econômica Aplicada; Fórum Brasileiro de Segurança Pública. Brasília: Rio de Janeiro: São Paulo: Instituto de Pesquisa Econômica Aplicada; Fórum Brasileiro de Segurança Pública.

BARDIN, Laurence. Análise de Conteúdo. Tradução de Luís Antero Reto, Augusto Pinheiro. São Paulo: Edições 70, 2016.

BAUER, Martin W; GASKELL, G. Pesquisa qualitativa com texto, imagem e som: um manual prático. Tradução de Pedrinho A. Guareschi. - Petrópolis, RJ : Vozes, 2002.

BIROLI, Flávia. Gênero e desigualdades: os limites da democracia no Brasil - 1a Ed. São Paulo: Boitempo, 2018.

BOURDIEU, Pierre. A dominação masculina: Tradução de Maria Helena Kiihner. Rio de Janeiro: Bertand Brasil, 1999.

BRASIL. Secretaria Especial de Políticas para as Mulheres. Lei Maria da Penha, $\mathbf{n}^{\circ}$ 11.340/2006: Coíbe a violência doméstica e familiar contra a mulher. Brasília, 2006.

BRASIL. Secretaria Especial de Políticas para as Mulheres. Política Nacional de Enfrentamento à Violência contra a Mulher. Brasília, 2011. Pacto Nacional pelo Enfrentamento à Violência Contra as Mulheres (PNEVCM).

CASTRO, Jorge Abrahão de. Política social alguns aspectos relevantes para a discussão. In: MDS/UNESCO. Concepção e gestão de proteção social não contributiva no Brasil. Brasília: Ministério do Desenvolvimento Social e Combate à Fome, UNESCO, 2009.

CRENSHAW, Kimberlé. Documento para o Encontro de Especialistas em Aspectos da Discriminação Racial Relativos ao Gênero. 2002. Disponível em: http://www.scielo.br/pdf/ref/v10n1/11636.pdf Acessado em: 05/04/2019.

COLLINS, Patrícia Hill. Pensamento feminista negro: conhecimento, consciência e política de empoderamento. 1ạ ed. São Paulo: Boitempo, 2019.

DAVIS, Angela. Mulheres, raça e classe [recurso eletrônico]; tradução Heci Regina Candiani. - 1. ed. - São Paulo : Boitempo, 2016. 


\section{coNGGESSOCIENCIAESOCIEDADE

GONÇALVES AS, Guará IMFR. Redes de proteção social na comunidade In: Guará IMFR, organizador. Redes de proteção social. São Paulo: Associação Fazendo História; 2010. p. 11-29.

HIRANO, Luis Felipe Kojima. Marcadores sociais das diferenças : fluxos, trânsitos e intersecções / Luis Felipe Kojima Hirano, Maurício Acuña; Bernardo Fonseca Machado (Org.). - Goiânia : Editora Imprensa Universitária, 2019.

HOOKS, B. Mulheres negras: moldando a teoria feminista. Revista Brasileira de Ciência Política, n. 16, 2015.

MARTINS, Ana Paula Antunes, CERQUEIRA, Daniel, MATOS, Mariana Vieira Martins. A institucionalização das políticas públicas de enfrentamento à violência contra as mulheres no Brasil. IPEA. 2015

MINAYO, Maria Cecília de Souza (org.). Pesquisa Social. Teoria, método e criatividade. 18 ed. Petrópolis: Vozes, 2001.

MOUTINHO, Laura. Diferenças e desigualdades negociadas: raça, sexualidade e gênero em produções acadêmicas recentes. Cad. Pagu, Campinas, n. 42, p. 201-248.

PISCITELLI, A. Interseccionalidades, categorias de articulação e experiências de migrantes brasileiras. Sociedade e Cultura, Goiânia, vol. 11, no 2, p. 263-274, 2008.

RODRIGUES, Marta Maria Assumpção. Políticas Públicas. São Paulo: Publifolha, 2010.

SAFFIOTI, Heleieth. Gênero, patriarcado e violência. São Paulo: Editora Fundação Perseu Abramo, 2004.

SCOTT, J. Gênero: uma categoria útil para análise histórica. Tradução de Christine Rufino Dabat e Maria Betânia Ávila. New York, Columbia University Press.1989. 